\title{
Summarized Coronary Artery Caliber and Left Ventricle Mass for Scoring of Cardiac Ischemia: Diagnostic and Prognostic Value
}

\author{
Edvardas Vaicekavicius \\ Clinic of Radiology, Lithuanian University of Health Sciences \\ Lithuania
}

\section{Introduction}

\subsection{Importance of methods for scoring coronary angiograms to reflect extent and severity of CAD}

Despite advances in modern medicine, the early detection of patients with obstructive coronary lesions remains an unresolved problem due to frequently occurring atypical, painless, and asymptomatic clinical variants of ischemic heart disease. For example, 80 to $90 \%$ of sudden cardiac deaths occur with a background of significant coronary artery disease (Zipes, 1998) and sudden death is often the first presentation of the cardiac disease. It is estimated that sudden death occurs in $33 \%$ to $70 \%$ of cardiac disease patients (Davies, 2000). In addition, an acute myocardial infarction (MI) usually develops in patients with multi-vessel coronary disease (Goldstein et al., 2000), while angiographic studies have shown that an acute MI may develop in coronary segments having only slight or moderate stenosis. It is well known that a ruptured atheromatous plaque in the coronary artery can initiate intracoronary thrombosis and occlusion with the subsequent development of an acute MI. However, plaque rupture with platelet activation and thrombus formation are more recognized as the key events in the pathogenesis of acute coronary syndrome than are the extent and severity of the coronary artery disease (CAD). Additionally, the symptoms of myocardial ischemia may not be caused by obstructive lesions in the coronary arteries at all. Myocardial ischemia may occur not only due to decreased blood flow through epicardial coronary arteries, but also because of the increased oxygen demand in patients with myocardial hypertrophy or hyperfunction. Myocardial hypertrophy may be the cause of cardiac arrhythmias due to coronary insufficiency in hypertensive patients. However, even in the absence of obstructive CAD, hypertensive patients frequently have angina or may show electrocardiographic abnormalities suggestive of myocardial ischemia due to coronary insufficiency (Vogt et al., 1992).

In this era of great achievements in cardiology, we are still in need of a convenient and informative coronary arteries analysis system that would allow us to quantitatively estimate the size and severity of atherosclerotic CAD and myocardial ischemia burden. 


\subsection{Consecutive steps in development of coronary scoring methods}

Initially, the purpose of creating methods to score coronary angiograms was to assess the severity of the underlying CAD and to determine whether the severity of angina and the degree of altered left ventricular function were closely correlated with the severity and extent of the underlying CAD. Multiple methods for evaluation and scoring of the coronary angiograms were created. However, there was no difference in the frequency of angina when the patients with the lowest coronary score were compared to patients with the highest coronary score (Leaman et al., 1981). Clinically, it is possible to have severe angina with one-vessel CAD or moderate angina with severe three-vessel CAD. Likewise, it is possible to have well-preserved left ventricular function with severe three-vessel CAD as well as to have severe left ventricular dysfunction with only one-vessel CAD.

Later, the coronary scores were used for risk stratification, because it was determined that the prognosis and outcomes in patients were in large part dependent on the extent (one-, two-, or three-vessel) and the severity of CAD (Ringqvist et al., 1983). This scoring system is still used today. Sullivan et al., (1990) developed a new angiographic scoring system for the extent of coronary disease (extent score). Therefore, the coronary scores seemed to be essential for the selection of a tailored therapeutic strategy. Subsequently, the coronary scores were used for the investigation of the relationship between the coronary lesion scores and the levels of serum lipoproteins (Hamsten et al., 1986; Jenkins et al., 1978). Eventually, a non-invasive coronary calcification scoring system became popular among investigators because coronary artery calcification strongly correlated with the severity of coronary atherosclerosis and the probability of obstructive disease (Kwon et al., 2011). The development of an invasive coronary scoring system would have to be much more effective in diagnosing and optimizing the treatment strategy, due to the fact that the non-invasive methods could not reflect the extent and severity of CAD.

In order to increase the value of the coronary scores in the selection of coronary patients for angioplasty, the American College of Cardiology/American Heart Association (ACC/AHA) in 1988 presented a system of classification of coronary lesions to predict the success and complications of balloon angioplasty (Krone et al., 2000). Although, the lesion type (A, B, or C) was not predictive of complications, specific lesion morphologies were predictive of adverse events and device use (Zaacks et al., 1998). Additionally, the type of lesion can impact the outcome of coronary bypass operations (Graham et al., 1999; Jalal, 2007). Thus, to choose an optimal revascularization strategy for patients with three-vessel and/or left-mainstem disease, there is one important requirement: to quantify the complexity of CAD while taking into account not only the number of significant lesions and their location, but also the complexity of each lesion independently. For this purpose, the SYNTAX scoring system was created (Garg et al., 2010; Sianos et al., 2005) The SYNTAX score was developed in order to characterize the coronary vasculature in terms of the number, functional impact, location, and complexity of the lesions.

However, in the myocardial infarction reperfusion era, it has become increasingly apparent that clinical outcomes are not only associated with coronary flow in the epicardial arteries but also with the quality of myocardial reperfusion. Quantitative angiographic indexes of coronary artery blood flow -- TIMI (thrombolysis in myocardial infarction) flow grades, corrected TIMI frame count, and TIMI myocardial perfusion grade -- gave new insights into the pathophysiology of acute coronary syndromes (Gibson 
et al., 1999, 2000, 2002; Korosoglou et al., 2007; Kunadian et al., 2009). Until recently, it was assumed that the blood flow in the non-culprit arteries in patients with acute coronary syndromes was normal. However, according to the data of Gibson et al., (2000) the coronary flow in the non-involved arteries in acute MI was, in fact, $40 \%$ slower than normal. It was also noted that the slower flow throughout all three arteries in acute MI could be associated not only with the extensive damage of microvasculature circulation but also might be the result of more extensive damage of non-culprit epicardial arteries. Greater lesion complexity might also be associated with poorer epicardial and myocardial perfusion.

\subsection{The new challenges for coronary scoring}

Because of these unresolved issues, it is imperative to extend the scope of investigations to include the impact of multi-vessel lesions in epicardial coronary arteries in order to elucidate the pathogenetic mechanism and prognosis of CAD. Therefore, we have created a completely new scoring system for the quantification of coronarography and ventriculography data. Using SYNTAX and other recent angiographic scoring methods, we often have no opportunity to assess the impact of myocardial mass and function on the myocardial ischemia and anginal severity. Hypertensive left ventricular hypertrophy is a powerful predictor of coronary events (Ghali et al., 1992; Koren et al., 1991) and develops due to impaired coronary blood flow autoregulation, decreased coronary reserve, increased minimal coronary vascular resistance, and carries an increased risk of cardiac death in the presence of coronary occlusion (Vogt et al., 1992). These events can be primarily dependent on the size and severity of the coronary lesions and on the functional and morphological status of the myocardium which requires a greater amount of blood for its nutrition. This new angiographic scoring system, which assesses the extent of coronary disease, myocardial mass, hypertrophy, and function, is simple to perform and it correlates better with the clinical symptoms of CAD.

\section{Methods and patients}

\subsection{Different technical solutions in calculation of coronary scores}

The exact quantification of total coronary artery damage is very complicated in clinical practice. Several different approaches have been proposed to determine the total coronary score: 1) the number of vessels diseased, 2) the number of proximal arterial segments diseased, 3) the proximal arterial segments score (Ringqvist et al., 1983), 4) the Friesinger index (Friesinger et al., 1970), 5) the modified Gensini index (Gensini et al., 1971), 6) the National heart and chest hospital (NHCH) index (Ringqvist et al., 1983), and 7) other methods. The most common problems with these methods were: 1) the interpretational differences in the estimation of the percentage of coronary artery narrowing due to differences in the selection of optimal reference diameter (Brown et al., 1977; Dodge et al., $1988), 2)$ the difficulties in the accurate assessment of the true hemodynamic value for each narrowing, 3) the difficulties in angiographic quantification of diffuse CAD (Graham et al., 1999; Jalal, 2007), and 4) the differences in techniques of measurements (Kalbfleisch et al., 1990). The hemodynamic value used by some authors is set only by the degree of narrowing. By other authors, the severity of luminal narrowing is weighted according to the 
usual flow to the left ventricle in each coronary vessel (Leaman et al., 1981) and according to the flow to muscle mass rather than to the actual volume of flow (Brandt et al., 1977; Gensini, 1983). However, it is difficult to accurately assess the coronary artery blood supply zones due to variable coronary artery dominance and multiple branching options. Still some authors tend to offset the impact of longevity of stenosis (Dodge et al., 1992) on myocardial blood flow.

However, the determined angiographic CAD scores in most cases had a poor correlation with the severity of angina pectoris and myocardial function. Therefore, the development of new coronary scoring methods needs a different approach from those which have been previously adopted for the accounting of coronary obstructions only.

\subsection{Technique for determination of summarized caliber of coronary arteries and left ventricle mass}

It is well established that the development and progression of CAD involves three processes: the reduction of the total caliber of coronary arteries, the increase in myocardium weight, and the deterioration of left ventricular pump function. Therefore, we have sought to create a specific coronary lesion scoring system which would avoid the subjectivity in the determination of degree of stenosis and in the selection of normal reference diameter which is highly variable and dependant on multiple variants in coronary dominance and branching.

The severity of the coronary lesion was expressed by the sum of residual calibers of all coronary arteries in the selected level. The extent of the coronary lesion was expressed by the calculation of the summarized caliber of three levels (Fig. 1). The narrowest diameters of the selected segments were used to calculate the coronary caliber expressed by coronary square area $\left(\mathrm{CSA}=0.785 \times \mathrm{D}^{2}\right)$. The assessment of the SCCA at the first coronary branching level included the sum of the cross-sectional areas at the narrowest points of the $1^{\text {st }}$ and $5^{\text {th }}$ segments, at the second level - the areas of the $2^{\text {nd }}, 6^{\text {th }}$, and $11^{\text {th }}$ segments, and at the third level - the areas of the $3^{\text {rd }}, 7^{\text {th }}, 9^{\text {th }}, 12^{\text {th }}$, and $13^{\text {th }}$ segments. The average of the arterial calibers at each level was considered to be the SCCA.

The computer-assisted calculating algorithm for SCCA is very simple, and coronary diameters can be measured using a quantitative analysis program readily available in almost every modern angiographic unit. We measured the narrowest diameters of each coronary segment in at least two projections of video images. In cases of uncommon variants of coronary dominance or branching, we also measured and summed all segments of the trunk below its second bifurcation.

Contrasting of the left ventricle was performed while the patient was taking a deep breath at the right anterior oblique $30^{\circ}$ body position. We performed a quantitative analysis of the ventriculographic data using the radial method (Fig. 2). We computed the end-systolic and diastolic volumes and estimated the myocardial mass by determining the wall thickness of the left ventricle. The end-systolic and end-diastolic volumes were calculated using the equation for spherical formations:

$$
\mathrm{V}=4 / 3 \Pi \mathrm{R}_{\mathrm{a}}^{3} \times \mathrm{K}
$$

In the equation above, we used the following abbreviations: $\mathrm{V}$ - systolic or diastolic volume, $\mathrm{R}_{\mathrm{a}}$ - average systolic or diastolic radius $(\mathrm{cm})$, and $\mathrm{K}-\mathrm{a}$ factor of correction. 


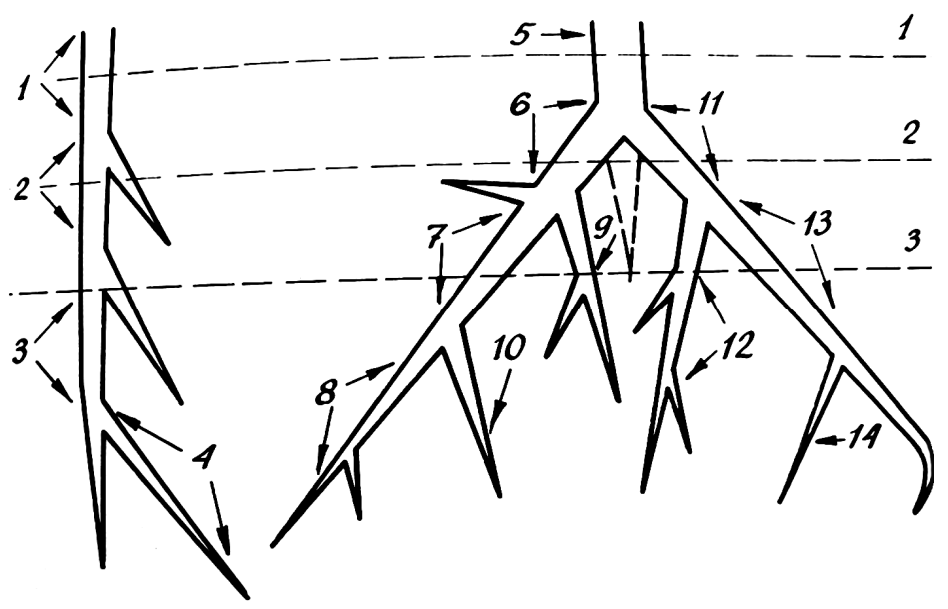

Fig. 1. A scheme of 15 segments of the coronary tree proposed by the American Heart Association which was used to calculate the summarized caliber of coronary arteries (SCCA). The cross-sectional areas in the narrowest points of the segments at each level were added together to represent the coronary caliber at one of the three coronary tree levels: above the first bifurcation, below the first bifurcation, or below the second bifurcation of the right and left coronary arteries. The average of the arterial calibers at the three levels was considered to be the average SCCA.

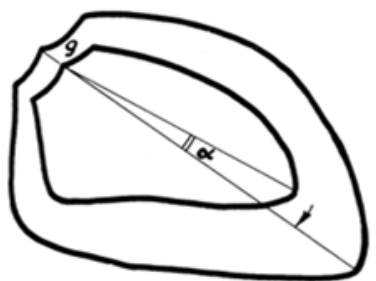

A

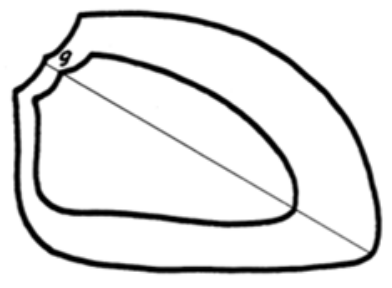

B

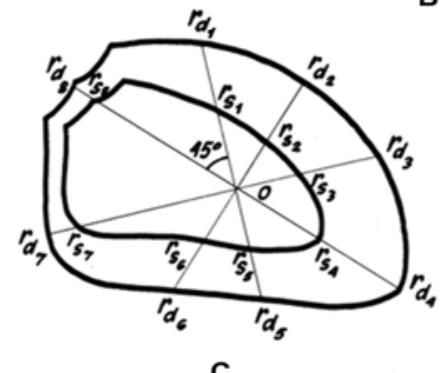

c

Fig. 2. Radial scheme used in the quantitative analysis of ventriculographic data: A -superposed end-systolic and end-diastolic profiles of the left ventricle with the a angle of apex rotation; B -- superposed end-systolic and end-diastolic contours after the correction of apex rotation; $\mathrm{C}$-- a scheme of radial delineation; we used the midpoint of the long axis of left ventricle (in diastole) to intersect the radial lines. 
We calculated the left ventricular mass using the thickness (h) of the anterior wall of the left ventricle using the following equation:

$$
\mathrm{LVM}=\left(4 / 3 \Pi \times\left(\mathrm{h}+\mathrm{R}_{\mathrm{a}}\right)^{3} \times \mathrm{K}-4 / 3 \Pi \mathrm{R}_{\mathrm{a}}{ }^{3} \times \mathrm{K}\right) \times 1.05
$$

In the equation above, we used the following abbreviations: LVM -- left ventricular mass, $h$ -- thickness of the anterior wall of left ventricle $(\mathrm{cm}), \mathrm{R}_{\mathrm{a}}$--average systolic or diastolic radius $(\mathrm{cm}), \mathrm{K}-$ a factor of correction, and 1.05 - a comparative weight of the myocardium $\left(\mathrm{g} / \mathrm{cm}^{3}\right)$. We measured the thickness of the anterior wall of the left ventricle at the midpoint between the aortic valve and the apex.

\subsection{Creation of the angiographic characteristics of myocardial supply 2.3.1 Angiographic coronary index}

Initially, the SCCA was indexed to the supplied left ventricular mass. This parameter was intended for the expression of the morphologic adequacy between the coronary artery tree and the supplied myocardial mass. This diagnostic criterion was entitled angiographic coronary index $(\mathrm{ACI})$ and was calculated according the formula:

$$
\mathrm{ACI}=(\mathrm{SCCA} / \mathrm{LVM}) \times 10
$$

In the equation above, we used the following abbreviations: ACI -- angiographic coronary index, SCCA -- summarized caliber of coronary arteries $\left(\mathrm{mm}^{2}\right)$, LVM - mass of the left ventricle (g), and 10 -- normalization factor used to reduce the average value of the index to 1. During the post-mortem examinations, we performed a post-mortem coronary angiography, an excision of coronary arteries by cutting them in intervals of $10 \mathrm{~mm}$ to analyze their luminal square areas by planimetry. An autopsy of both ventricles was performed with the separation of its masses with and without fatty tissues. We found that the patients without any cardiovascular disease had the SCCA-to-LVM ratio approximately equal to 1 . The ratio was also almost the same as in the control group of patients who had no CAD symptoms.

\subsubsection{Angiographic anginal index}

Myocardial quantity (mass) does not represent the quality of myocardial tissue nor its viability or its demand for arterial supply; instead, the greater myocardial mass usually represents a lower functional status. To represent the functional status of the myocardium, we used a ratio between the angiographic coronary index (ACI) and the ejection fraction of the left ventricle (LVEF). We named the ratio an anginal index, because we noticed a very prominent negative correlation between this index and the intensity of angina. However, there was no correlation between the ACI and LVEF.

When the ACI exceeded 1.0 and the ACI was higher than the LVEF, the inadequacy between the blood supply and the demand was theoretically absent. In contrast, when the ACI was less than the LVEF, the inadequacy was present. The angiographic anginal index in these cases was less than 1.0. Therefore, the angiographic anginal index allowed us to express quantitatively the favorable conditions for myocardial ischemia.

\subsubsection{Angiographic prognostic index}

The complete characterization of the myocardial perfusion state and its prognostic impact on the follow-up results using only the ACI-to-LVEF ratio was not possible. For example, 
in patients with decreased SCCA and low LVEF (due to the presence of post-infarction myocardial scars) the ratio did not show the inadequacy between the blood supply and demand and masked the poor prognosis for these patients. Both the diminished SCCA and the lowered LVEF may equally increase risk in patients. Therefore, the compound of ACI and LVEF was labeled angiographic prognostic index (API). It was calculated using this equation:

$$
\mathrm{API}=\mathrm{ACI}+\mathrm{LVEF}=(\mathrm{SCCA} / \mathrm{LVM})+\mathrm{LVEF}
$$

In the equation above, the API stands for the angiographic risk index, ACI -- angiographic coronary index, SCCA -- summarized caliber of coronary arteries $\left(\mathrm{mm}^{2}\right), \mathrm{LVM}$ - mass of the left ventricle $(\mathrm{g})$, and LVEF - ejection fraction of the left ventricle.

\subsection{Patient groups}

In this way, we have quantitatively analyzed coronarographic and ventriculographic data in 403 patients with different clinical forms of ischemic heart disease. All patients were divided into groups according to the size and severity of coronary obstructions and the left ventricular mass. There were $59(14.6 \%)$ patients with normal coronary arteries, $165(40.9 \%)$ patients with arteries narrowed up to $50 \%$ of diameter, and $179(44.4 \%)$ patients with lesions which obstructed more than $50 \%$ of the coronary artery diameter. Among patients with coronary narrowing of up to $50 \%, 88(24.8 \%)$ patients had a normal ventricular weight and $77(19.1 \%)$ had an increased weight of the left ventricle. The patients with increased left myocardial weight were divided into two subgroups: the cardiomyopathy (obstructive and hypertrophic) subgroup and the secondary hypertrophy due to hypertension subgroup. The majority of patients $(82$ or $45.8 \%$ ) with obstructions of more than $50 \%$ had coronary disease of a single branch, $67(37.4 \%)$ patients had disease in two branches, and the remaining 30 $(16.7 \%)$ patients had lesions in all three branches. Twenty six $(14.5 \%)$ patients had left main coronary artery disease. The average age of patients was $47.8 \pm 0.4$ years. The dominant gender was male (95.5\%). Additionally, patients were divided into groups according to clinical diagnosis (stable angina pectoris, post-infarction angina, hypertensive cardiopathy, and hypertrophic cardiomyopathy). The follow-up results after 2 to 7 years were analyzed in 136 patients with CAD (52 underwent surgery, and 84 were treated conservatively). Thirteen of these patients died after surgical intervention, and nineteen died after conservative treatment.

We performed 176 necropsy examinations with postmortem coronarography and epicardial excision of the coronary trunks. The trunks were cut in slices for morphologic analysis and the myocardium of the right and left ventricles was separated into three parts according to the supply zones of the anterior descending artery, the circumflex branch of the left coronary artery, and the right coronary artery. The majority $(n=146)$ of these patients died from CAD: 70 patients experienced sudden death and the rest died from different complications of CAD. Three control groups were formed from the remaining 30 patients who died from other, non-cardiac diseases: the 1st control group was comprised of patients who died younger than age 50, the second control group was comprised of patients who died older than age 50, and the third control group included patients of any age who died having signs of cardiac hypertrophy without any obstructions in the coronary arteries. 


\subsubsection{Statistical analysis}

The study data was processed using STATISTICA 5 and SPSS 10 (Statistical Package for Social Science) software. All data were presented as mean values \pm standard deviations. The following statistical methods of analysis were used: paired t-test for differences in groups, $\mathrm{t}$ test for differences between two groups, ANOVA for differences between multiple groups, and chi-square $\left(X^{2}\right)$ - for categorical data. A p-value less than 0.05 was regarded as statistically significant.

\section{Results}

\subsection{Calculation of angiographic coronary index using autopsy data}

The necropsy study consisted of the following parts: 1) performance of the post-mortem coronary angiography (Fig. 3A); 2) the longitudinal excision of contrasted coronary artery trunks from the myocardial tissue and cutting them into $10 \mathrm{~mm}$-long pieces for microscopic analysis, and 3) the division of the myocardial mass of both ventricles (with and without fatty tissues) into three parts according to the supply regions of the right coronary artery, the circumflex branch and the anterior descending artery (Fig. 3B).
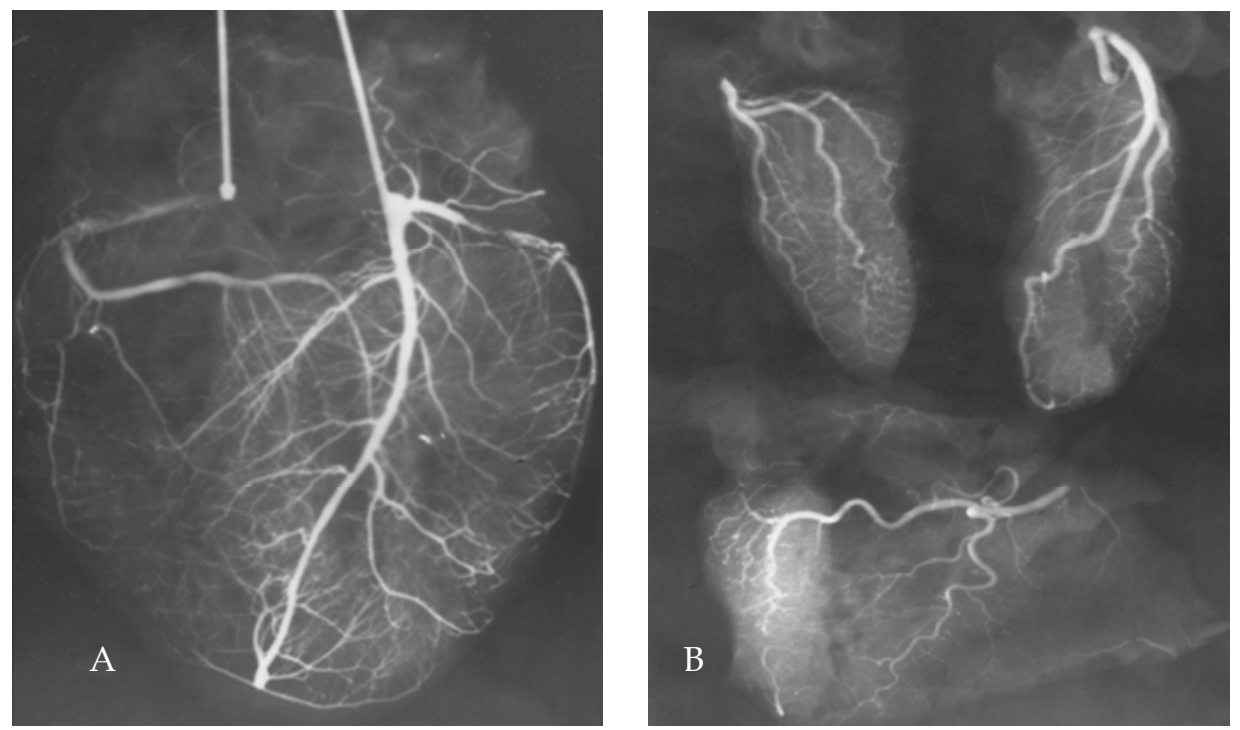

Fig. 3. The anteroposterior view of postmortem coronary angiography (A). Myocardial cutting into parts differing according to blood supply regions: in the upper left position is the part supplied by the circumflex branch, in the upper right is the part supplied by anterior descending artery, and in the bottom is the part supplied by the dominant right coronary artery (B).

The coronary arteries were contrasted with $40 \%$ solution of $\mathrm{BaSO}_{4}$. The contrast material was injected using $120 \mathrm{mmHg}$ pressure through a special cannula inserted and fixed into the orifice of the right and left coronary arteries (Fig. 3). The coronarograms were made after the stagnation of contrast material. The measurements of the coronary arteries were 
performed using the methodology for the determination of SCCA. The second step was supplemented by weighing the different parts of the myocardium, by calculation of the coronary caliber, and by the assessment of the three separate ACIs for each coronary artery.

The examination of the arterial cuts revealed the diffuse nature of the obstructive lesions in patients who died suddenly or died after complications of chronic heart disease. In the control group of younger patients, the slight narrowing (less than 50\%) covered only 5.9 $8.1 \%$ of the coronary artery length. In the second control group of older patients, the same lesions covered 9.8 to $13.3 \%$ of coronary artery length. However, in patients who died from CAD, the total length of the obstructed segments covered from $73.6 \%$ to $91.6 \%$ of coronary artery length; furthermore, one-half of the segments had less than $50 \%$ narrowing. This means that the quantitative estimation of the degree of stenosis using the referential normal adjacent segment for calculation may often be incorrect.

The assessment of the coronary artery diameter without the calculation of the degree of stenosis is more objective. The SCCA in control patients was almost the same at each level and there were no significant differences between the control groups. However, the difference between each level SCCA of the two groups of died patients, from one side, and of the three control groups, from other side, was noticed (Table 1). These findings are a consequence of differences in the size, location, and severity of obstruction in CAD patients. At the same time the decrease in SCCA with the simultaneous increase in myocardial weight was fixed in patients who died from sudden coronary death or from CAD complications (Table 2).

\begin{tabular}{|l|c|c|c|c|}
\hline \multirow{2}{*}{ Patient groups } & \multirow{2}{*}{$\begin{array}{c}\text { No. } \\
\text { of } \\
\text { pts. }\end{array}$} & 1st level & 2nd level & 3rd level \\
\cline { 3 - 5 } & 12 & $27.1 \pm 5.2$ & $29.1 \pm 1.5$ & $24.8 \pm 4.2$ \\
\hline $\begin{array}{l}1^{\text {st }} \text { control group } \\
\text { (age 34.2 } \pm \text { 10.2 yrs.) }\end{array}$ & 9 & $25.2 \pm 5.4$ & $25.6 \pm 6.0$ & $25.0 \pm 4.6$ \\
\hline $\begin{array}{l}2^{\text {nd }} \text { control group } \\
\text { (age 67.5 } \pm \text { 9.7 yrs.) }\end{array}$ & 9 & $23.6 \pm 7.2$ & $25.6 \pm 5.6$ & $24.3 \pm 4.5$ \\
\hline $\begin{array}{l}3^{\text {rd }} \text { control group } \\
\text { (LV hypertrophy) }\end{array}$ & 7 & $14.9 \pm 6.8$ & $7.58 \pm 3.3$ & $11.7 \pm 4.2$ \\
\hline $\begin{array}{l}4^{\text {th }} \text { group (sudden } \\
\text { coronary death) }\end{array}$ & 14 & $12.9 \pm 7.4$ & $10.3 \pm 4.0$ & $7.8 \pm 4.7$ \\
\hline $\begin{array}{l}5^{\text {th }} \text { group (death from } \\
\text { CAD complications) }\end{array}$ & 17 & & \\
\hline
\end{tabular}

Table 1. The summarized caliber of coronary arteries of three levels in different groups of died patients.

The post-mortem assessment of the ACI in the first and second control groups has shown that the value of the ACI slightly exceeded 1. Additional analysis showed that the ACI of the right coronary artery was lower than the ACI of the left coronary artery $(p<0.03)$. This distinction could be caused by functional peculiarities of both ventricles. Because the SCCA was almost the same in all three groups, the diminished ACI in the third group was associated with the increased weight of the myocardium. However, the SCCA in patients of 
the fourth and the fifth groups with CAD was significantly smaller, and the ACI was consequently low, also.

\begin{tabular}{|l|c|c|c|c|}
\hline \multirow{2}{*}{ Patient groups } & \multirow{2}{*}{$\begin{array}{c}\text { No. } \\
\text { of } \\
\text { pts. }\end{array}$} & $\begin{array}{c}\text { Average SCCA, } \\
\mathrm{mm}^{2}\end{array}$ & ACI & $\begin{array}{c}\text { Myocardial } \\
\text { mass without } \\
\text { lipid tissue, }\end{array}$ \\
\hline $\begin{array}{l}\text { 1st control group } \\
\text { (age 34.2 } \pm 10.2 \text { yrs.) }\end{array}$ & 12 & $27.2 \pm 3.9$ & $1.41 \pm 3.90$ & $226.4 \pm 11.0$ \\
\hline $\begin{array}{l}\text { 2nd }^{\text {nd }} \text { control group } \\
\text { (age 67.5 } \pm .7 \text { yrs.) }\end{array}$ & 9 & $25.3 \pm 4.4$ & $1.42 \pm 0.16$ & $209.9 \pm 12.2$ \\
\hline $\begin{array}{l}\text { 3rd control group } \\
\text { (LV hypertrophy) }\end{array}$ & 7 & $25.0 \pm 4.4$ & $0.84 \pm 0.06$ & $337.8 \pm 4.90$ \\
\hline $\begin{array}{l}4^{\text {th }} \text { group (sudden } \\
\text { coronary death) }\end{array}$ & 14 & $11.1 \pm 3.2$ & $0.14 \pm 0.04$ & $306.0 \pm 17.6$ \\
\hline $\begin{array}{l}5^{\text {th }} \text { group (death from } \\
\text { CAD complications) }\end{array}$ & 17 & $9.9 \pm 4.5$ & $0.22 \pm 0.04$ & $305.1 \pm 12.7$ \\
\hline
\end{tabular}

Table 2. The SCCA, ACI, and myocardial mass in different groups of deceased patients.

Six sudden death patients in the fourth group had no obvious segmental obstructions in their coronary arteries; however, the ACI was significantly lower $(0.62 \pm 0.01)$ than the control values $(p<0.001)$. The lowered ACI was caused by increased left ventricular weight and lowered SCCA, compared to the control groups. The detailed analysis of the myocardium in these patients did not revealed any signs of myocardial infarction. We may assume that the relative insufficiency could be the starting mechanism for the expressed myocardial ischemia and for the possible life threatening arrhythmia. This background factor of inadequacy between the SCCA and the myocardial mass could be a cause of the sudden coronary death.

\subsection{Assessment of angiographic characteristics of myocardial supply (ACMS) in clinical setting}

Various authors have expressed difficulties in creating an unbiased angiographic coronary scoring system intended for researchers as well as for clinical practice. In particular, all the diagnostic and prognostic capabilities of angiographic coronary scoring remain undetermined.

\subsubsection{Difficulties in assessment of angiographic coronary scores associated with the anatomical variability of coronary dominance and branching}

Because only three types of anatomic variants of coronary dominance are commonly used in previous scoring systems and all possible coronary branching types are not taken into consideration, the hemodynamic value of each stenosis might be calculated inaccurately.

We have analyzed the impact of coronary dominance on the diameters of all fifteen coronary segments while using not three but six types of coronary dominance. The six types were determined using the ratio between the myocardial mass supplied by the right and the myocardial mass supplied by the left coronary arteries. Using a topographic scheme shown in Fig. 4, we have calculated the ratio by delineating myocardial zones supplied by the right 
and left coronary arteries. Coronarograms performed in the left and right anterior oblique $30^{\circ}$ views are shown in the upper part of the figure. The views are most informative in understanding the branching peculiarities of both coronary arteries supplying the posterior and inferior walls of the left ventricle. A percept used to calculate the amount of myocardial tissue supplied by the right and left coronary arteries is shown in the lower part of the picture. This approach was chosen according the information obtained from post-mortem studies. The whole myocardial tissue (mass) was assigned 20 conceptual mass units. Five units were assigned to the right ventricle, another five to the septum ( 3 units to the anterior and 2 units to the posterior septum), and the remaining 10 units were assigned to the mass of the left ventricle divided into ten equal parts.
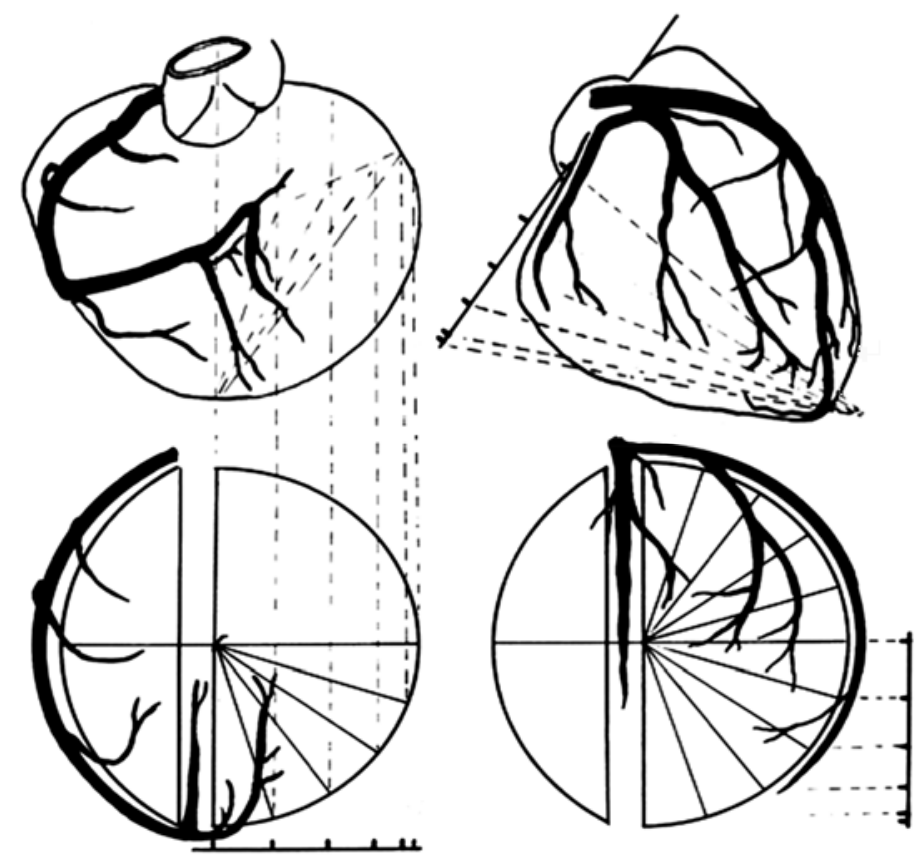

Fig. 4. Topographic schemes reflecting the delineation and calculation of myocardial zones and mass supplied by the right and left coronary arteries. The lines divide myocardial tissue of the left ventricle into 10 zones (units), each of similar mass. Using the same principle, the right ventricle was assigned 5 units, the anterior septum -- 3 units, and the posterior septum -- 2 units.

Using this technique we could quantitatively define all possible variants of coronary blood supply to the right and left myocardial masses. To indicate the type of coronary dominance we used the ratio between myocardial masses supplied by the right and left coronary arteries. We used the R:L notation (where $\mathrm{R}$ and $\mathrm{L}$ correspond to the number of mass units supplied by the right and left coronary arteries). For example, the 5:15 ratio would indicate that 5 units were assigned to the right, and 15 units to the left myocardial supply zone. We have encountered the six most common variants of coronary dominance -- 5:15 (potentially, 
the variant of the left dominance), 6:14; 7:13; 8:12; 9:11, and 10:10 (potentially, the variant of the right dominance).

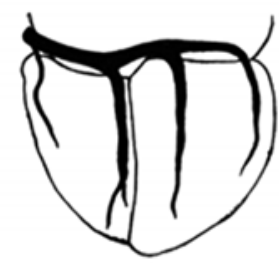

A

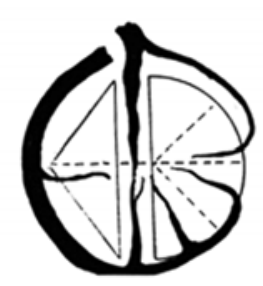

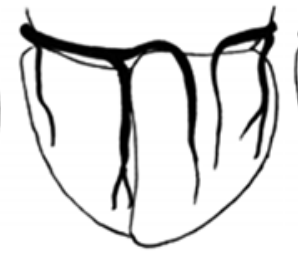

B

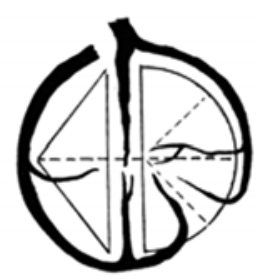

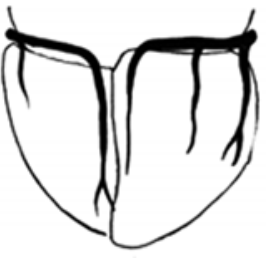

C

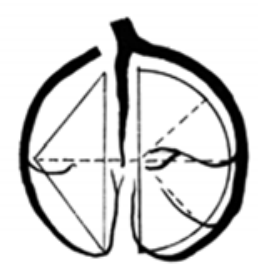

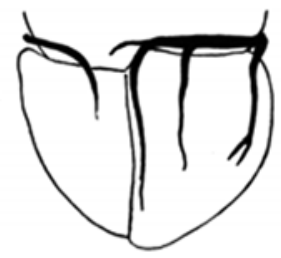

D

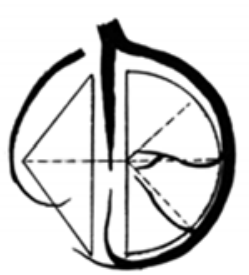

Fig. 5. The quantitative expression of coronary dominance: A, 12:8; B, 9:11; C, 6:14; D, 4:16.

The usage of the right-to-left myocardial mass ratio allowed us to define the coronary dominance variants more precisely (Fig. 5). Dividing control patients into the six groups (according to the most common coronary dominance variants) allowed us to obtain significant differences in segment diameters of the circumflex branch of the left coronary artery and the right coronary artery between all groups. However, there was no statistical difference between all groups according to the segments of the left anterior descending artery, because the caliber of these segments is more stable with respect to the variations in coronary dominance.

We have identified the four most frequent variants of coronary branching (Fig. 6) while using these topographic schemes for a more thorough analysis of the coronary supply zones. It is interesting to note that the following four variants of coronary branching had the exact same ratio of coronary dominance determined by the myocardial supply zones. However, the correlation between the caliber of the coronary segments and the size of their myocardial supply zones was found to be very high $(\Gamma=0.96)$ despite the variability of coronary dominance and branching. This finding shows the fundamental importance of assessing the contiguous segments to estimate the real degree of stenosis, because diameters of adjacent arterial segments usually visible in coronarograms may be diminished because of the diffuse obstructive changes in adjacent coronary arteries, and it becomes very difficult to decide whether the particular segment is damaged or not. Therefore, the assessment of the coronary lesion score using SCCA appears to be more objective; it does not require consideration of the coronary dominance and branching. At the same time, the location and degree of atherosclerotic obstructions may be detected automatically by measuring the diameter of the narrowest point in every segment at several levels. Therefore, to increase the accuracy of coronary scoring, it is important to calculate the SCCA in a higher number of levels. 


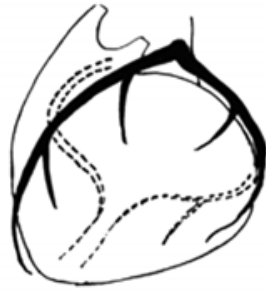

A

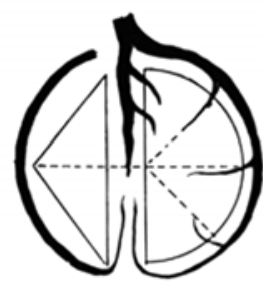

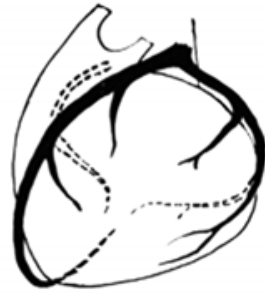

B

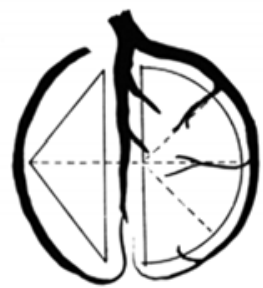

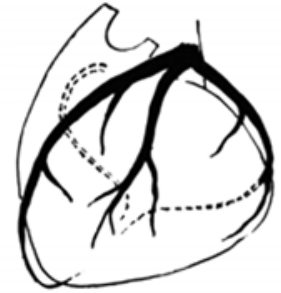

C

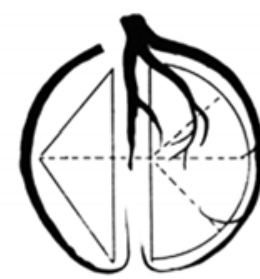

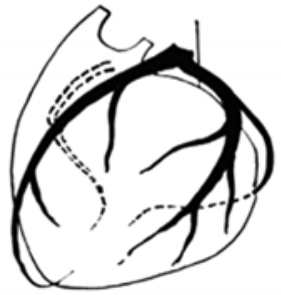

D

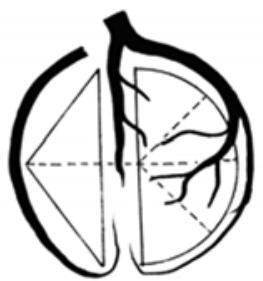

Fig. 6. The most frequent variants of coronary branching: A, common (6:14); B, left anterior descending dominance (6:14); C, trifurcation (6:14); and D, marginal (6:14).

\subsubsection{Correlation between summarized caliber of coronary arteries and different angiographic coronary scores}

We have analyzed the correlation between the data obtained by SCCA and by other coronary scores. The diagnostic features of the Friesinger, Leaman, and Gensini scores or indexes dedicated for the quantitative expression of the extent and severity of CAD were compared with each other and with SCCA.

The Friesinger index ranges from 0 to 15 . Each of the three main coronary arteries is scored separately from zero to five. The scores are: 0 -- no arteriographic abnormalities; 1 - a trivial luminal narrowing less than 29\%; 2 - a localized 30 to $68 \%$ luminal narrowing; 3 -- multiple 30 to $68 \%$ luminal narrowing; 4 -- 69 to 100\% luminal narrowing without $100 \%$ occlusion of proximal segments; and 5 -- total obstruction of a proximal segment.

The Leaman index has another weighting system. If the vessel was totally occluded, the coronary artery segment value was multiplied by 5.0. If there was a 90 to $99 \%$ occlusion, it was multiplied by 3.0. For a 70 to $89 \%$ obstruction, it was multiplied by 1.0. The segmental scores were then added to derive the total coronary score.

The modified Gensini index assigns a heavier weight to the more severe luminal narrowing (Gensini, 1983). Weights are also assigned to each segment depending on vessel size and importance; segments serving larger regions of myocardium are more heavily weighted. For example, the left main coronary artery receives the heaviest weight. Each arterial segment is weighted by a value from 0.5 to 5.0. (The weight for segments 1 through 4 is changed to 0.5 if the system is left dominant.) The stenosis is weighted from 2 to 64 . The product of these two weights is the total weight for each arterial segment. The modified Gensini index is the sum of the total weights for each segment. For each segment the two weights are multiplied. The sum of the products is the modified Gensini score.

So, we have compared fundamentally different angiographic coronary scoring methods taking into account: 1) the degree of stenosis regarding the diameters of adjacent segments, 
2) the degree (weight) of stenosis for each segment regarding the three types of coronary dominancy, and 3) the average SCCA. The comparative analysis of different scoring methods showed that the lowest correlation was observed between the methods that were based on different coronary scoring principles. For example, Friesinger index has only moderate correlation with ACI $(r=-0.45)$. The correlation between Gensini index and ACI was only insignificantly better $(r=-0.54)$. However, the correlation between Friesinger and Gensini indexes was high $(\mathrm{r}=0.84)$.

\subsection{Value of angiographic characteristics of myocardial supply in diagnostic improvements}

Primarily, we investigated the relationship between angiographic characteristics of myocardial supply (ACMS), on the one hand, and clinical symptoms of myocardial ischemia and clinical forms of ischemic heart disease, on the other hand. For the expression of myocardial supply features by angiographic characteristics, we have chosen what we consider the three most important summarized indices of all angiographic indices, namely, the angiographic coronary index (ACI), the angiographic anginal index (AAI), and the angiographic prognostic index (API).

\subsubsection{Interrelation between clinical symptoms of CAD and the angiographic characteristics of myocardial supply}

The dependence of ACMS from the functional class of angina pectoris determined according to the classification of Canadian Cardiovascular Society is shown in Table 3. The data show that there is a very well defined relationship between all ACMS and the clinical severity of anginal symptoms. In addition, we have analyzed the relationship between the ACMS and the character of anginal pain (Table 4). Patients were divided into 3 groups: the $1^{\text {st }}$ group consisted of patients with atypical prolonged anginal pain, the $2^{\text {nd }}$ group -- of patients with typical anginal symptoms, and the $3^{\text {rd }}$ group -- of patients who had typical pain but after an effective treatment of acute MI the anginal symptoms disappeared.

\begin{tabular}{|c|c|c|c|c|c|}
\hline $\begin{array}{c}\text { Class of } \\
\begin{array}{c}\text { Angina } \\
\text { Pectoris }\end{array}\end{array}$ & $\begin{array}{c}\text { No. of } \\
\text { pts. }\end{array}$ & $\begin{array}{c}\text { SCCA, } \\
\mathrm{mm}^{2}\end{array}$ & $\begin{array}{c}\text { ACI } \\
\text { (SCCA / LV mass) }\end{array}$ & $\begin{array}{c}\text { AAI } \\
(\mathrm{ACI} / \mathrm{LVEF})\end{array}$ & API (ACI+EF) \\
\hline $1^{\circ}$ & 49 & $23.4 \pm 1.0$ & $0.68 \pm 0.03$ & $1.0 \pm 0.06$ & $0.78 \pm 0.07$ \\
\hline $2^{\circ}$ & 21 & $18.0 \pm 1.1$ & $0.49 \pm 0.04$ & $0.8 \pm 0.08$ & $0.45 \pm 0.08$ \\
\hline $3^{\circ}$ & 22 & $13.2 \pm 0.7^{*}$ & $0.39 \pm 0.05$ & $0.6 \pm 0.03$ & $0.23 .9 \pm 0.14$ \\
\hline \multirow{3}{*}{$\mathrm{P}$} & 1 vs. 2 & 0.001 & 0.001 & 0.019 & 0.006 \\
\cline { 2 - 6 } & 1 vs. 3 & 0.001 & 0.013 & 0.007 & 0.007 \\
\cline { 2 - 6 } & 2 vs. 3 & 0.005 & 0.009 & 0.05 & 0.05 \\
\hline
\end{tabular}

Table 3. ACMS in patients with different functional class of angina pectoris.

All angiographic characteristics were worse in patients with typical angina (2nd group) compared to patients with atypical chest pain (1 ${ }^{\text {st }}$ group). Similar significant differences were discovered between the $1^{\text {st }}$ and $3^{\text {rd }}$ groups of patients who did not have the postinfarction angina. The patients who did not have the post-infarction angina also had worse average SCCA, ACI, and anginal index. It is interesting that there were no differences in ACMS between patients in the $2^{\text {nd }}$ (typical angina) and $3^{\text {rd }}$ groups (no post-MI angina). 


\begin{tabular}{|c|c|c|c|c|c|}
\hline $\begin{array}{c}\text { Character of } \\
\text { anginal pain }\end{array}$ & $\begin{array}{c}\text { No. of } \\
\text { pts. }\end{array}$ & $\begin{array}{c}\text { Average } \\
\text { SCCA, } \\
\mathrm{mm}^{2}\end{array}$ & $\begin{array}{c}\text { ACI } \\
\text { (SCCA / LV mass) }\end{array}$ & $\begin{array}{c}\text { AAI } \\
\text { (ACI / LVEF) }\end{array}$ & $\begin{array}{c}\text { API } \\
(\text { ACI+EF })\end{array}$ \\
\hline $1^{\circ}$ atypical AP & 49 & $27.3 \pm 1.2$ & $71.1 \pm 4.1$ & $1.0 \pm 0.05$ & $\begin{array}{c}0.71 \pm \\
0.07\end{array}$ \\
\hline $2^{\circ}$ typical AP & 21 & $20.8 \pm 1.2$ & $57.2 \pm 2.9$ & $0.83 \pm 0.06$ & $\begin{array}{c}0.48 \pm \\
0.05\end{array}$ \\
\hline $\begin{array}{l}3^{\circ} \text { disappeared } \\
\text { post-MI AP }\end{array}$ & 22 & $22.9 \pm 2.2$ & $48.7 \pm 4.4$ & $1.33 \pm 0.1$ & $0.63 \pm 0.1$ \\
\hline \multirow{2}{*}{$\mathrm{P}$} & 1 vs. 2 & 0.001 & 0.009 & 0.05 & 0.05 \\
\cline { 2 - 6 } & 1 vs. 3 & 0.05 & 0.001 & 0.05 & \\
\cline { 2 - 6 } & 2 vs. 3 & & & 0.004 & \\
\hline
\end{tabular}

Table 4. Angiographic characteristics of myocardial supply in patients with different character of anginal pain. The statistical significance of the differences in angiographic characteristics between the three different characters of anginal pain is shown in the lower part of the table.

However, the difference in the angiographic anginal index between these three groups existed not because of the difference in SCCA but because of the difference in leftventricular ejection fraction that was evidently lower in post-MI patients. Furthermore, there was no inadequacy between the diminished SCCA and the diminished left-ventricular ejection fraction in post-infarction patients.

\subsubsection{Interrelation between clinical forms of coronary artery disease and angiographic characteristics of myocardial supply}

We have studied the levels of ACMS in patients divided into groups according to the different clinical forms of ischemic heart disease. The values of different ACMS obtained from patients with different clinical diagnoses of ischemic heart disease are shown in Table 5. The SCCA was highest in control patients and lowest in patients with multivessel CAD. The SCCA of all patients groups with CAD was lower compared with the groups without CAD. This consistent pattern was observed in the comparison of patients according to ACI, except that the ACI was the same in patients with one vessel disease and in patients with myocardial hypertrophy. The same regularity was noted between groups compared according to AAI and API. The anginal syndrome was expressed mostly in patients with multi-vessel disease. The AAI and API were equally expressed between patients with onevessel disease and patients with myocardial hypertrophy.

The various ACMS in patients with different clinical forms of myocardial infarction are shown in table 6 . The $1^{\text {st }}$ group included patients with myocardial infarction without ST segment elevation (NSTEMI). The $2^{\text {nd }}$ group included patients with ST elevation myocardial infarction (STEMI).

After comparing both groups of patients, we noticed that NSTEMI and STEMI were significantly different according to AAI and API only. The SCCA and ACI differed insignificantly. The API was worse in NSTEMI patients. Similar findings confirm the studies of other authors. 


\begin{tabular}{|l|c|c|c|c|c|}
\hline \multicolumn{1}{|c|}{ Diagnosis } & $\begin{array}{c}\text { No. of } \\
\text { pts. }\end{array}$ & SCCA, $\mathrm{mm}^{2}$ & $\begin{array}{c}\text { ACI } \\
\text { (SCCA / LV mass) }\end{array}$ & $\begin{array}{c}\text { AAI } \\
\text { (ACI / LVEF) }\end{array}$ & API (ACI+EF) \\
\hline $\begin{array}{l}\text { Stable AP in } \\
\text { patients with } \\
\text { one-vessel } \\
\text { disease }\end{array}$ & 101 & $18.9 \pm 0.66^{1}$ & $57.2 \pm 2.32^{2}$ & $0.82 \pm 0.04^{3}$ & $128.4 \pm 2.75^{4}$ \\
\hline $\begin{array}{l}\text { Stable AP in } \\
\text { patients with } \\
\text { multi-vessel } \\
\text { disease }\end{array}$ & 34 & $12.6 \pm 1.40$ & $30.3 \pm 3.47$ & $0.50 \pm 0.07$ & $93.7 \pm 5.06$ \\
\hline $\begin{array}{l}\text { Stable post- } \\
\text { infarction AP }\end{array}$ & 96 & $18.7 \pm 0.83^{1}$ & $49.2 \pm 2.41$ & $1.04 \pm 0.07$ & $101.9 \pm 3.40$ \\
\hline $\begin{array}{l}\text { Stable AP with } \\
\text { myocardial } \\
\text { hypertrophy \& } \\
\text { insignificant } \\
\text { CAD }\end{array}$ & 110 & $23.7 \pm 0.64$ & $56.0 \pm 1.36^{2}$ & $0.82 \pm 0.024^{3}$ & $127.2 \pm 2.09^{4}$ \\
\hline $\begin{array}{l}\text { Controls } \\
\text { without CAD } \\
\text { and AP }\end{array}$ & 35 & $32.8 \pm 1.23$ & $95.2 \pm 4.44$ & $1.5 \pm 0.091$ & $163.2 \pm 6.0$ \\
\hline
\end{tabular}

Table 5. ACMS in different groups of patients with ischemic heart disease. Statistically significant differences $(\mathrm{P}<0.01)$ were found between all groups of patients, except the groups shown in superscript.

\begin{tabular}{|c|c|c|c|c|c|}
\hline $\begin{array}{c}\text { MI in } \\
\text { anamnesis }\end{array}$ & $\begin{array}{c}\text { No. of } \\
\text { pts. }\end{array}$ & $\begin{array}{c}\text { SCCA, } \\
\mathrm{mm}^{2}\end{array}$ & $\begin{array}{c}\text { ACI } \\
(\text { SCCA } / \text { LV mass })\end{array}$ & $\begin{array}{c}\text { AAI } \\
(\mathrm{ACI} / \mathrm{LVEF})\end{array}$ & $\begin{array}{c}\text { API } \\
(\mathrm{ACI}+\mathrm{EF})\end{array}$ \\
\hline $\begin{array}{l}\text { NSTEMI } \\
\left(1^{\text {st }} \text { group }\right)\end{array}$ & 21 & $18.1 \pm 1.0$ & $51.7 \pm 3.2$ & $0.93 \pm 0.08$ & $0.45 \pm 0.05$ \\
\hline $\begin{array}{l}\text { STEMI } \\
\left(2^{\text {nd }} \text { group }\right)\end{array}$ & 22 & $21.3 \pm 1.1$ & $55.1 \pm 5.5$ & $0.75 \pm 0.04$ & $0.79 \pm 0.08$ \\
\hline P value & 2 vs. 3 & & & 0.001 & 0.008 \\
\hline
\end{tabular}

Table 6. ACMS in groups of patients with different clinical forms of myocardial infarction.

\subsection{Evaluation of angiographic characteristics of myocardial supply in predicting of outcomes}

Death of cardiac origin has occurred in only 32 out of 136 patients analyzed during the seven-year follow-up period. We did not notice any progression of disease after 3 to 7 years in 40 patients with CAD who had a slightly lower ACI and left-ventricular ejection fraction but normal prognostic index. We performed a detailed analysis of ACMS indices in patients who died within three years (Table 7). 


\begin{tabular}{|c|c|c|c|c|c|c|}
\hline $\begin{array}{l}\text { Myocardial } \\
\text { infarction } \\
\text { in } \\
\text { anamnesis }\end{array}$ & $\begin{array}{l}\text { No. of } \\
\text { pts. }\end{array}$ & $\begin{array}{l}\text { SCCA, } \\
\mathrm{mm}^{2}\end{array}$ & LVEF & $\begin{array}{c}\mathrm{ACI} \\
\text { (SCCA / } \\
\text { LV mass) }\end{array}$ & $\begin{array}{c}\text { AAI } \\
(\mathrm{ACI} / \mathrm{LVEF})\end{array}$ & $\begin{array}{c}\text { API } \\
(\mathrm{ACI}+\mathrm{EF})\end{array}$ \\
\hline $\begin{array}{l}\text { Death } \\
\text { during the } \\
3^{\text {rd }} \text { year } \\
\text { (1 } 1^{\text {st }} \text { group) }\end{array}$ & 7 & $20.7 \pm 8.2$ & $0.53 \pm 0.03$ & $0.51 \pm 0.04$ & $0.98 \pm 0.03$ & $\begin{array}{c}1.04 \pm \\
0.05\end{array}$ \\
\hline $\begin{array}{l}\text { Death } \\
\text { during the } \\
2^{\text {nd }} \text { year } \\
\text { (2nd } \text { group) }\end{array}$ & 5 & $22.7 \pm 6.6$ & $0.29 \pm 0.03$ & $0.31 \pm 0.05$ & $1.07 \pm 0.05$ & $\begin{array}{c}0.60 \pm \\
0.08\end{array}$ \\
\hline $\begin{array}{l}\text { Death } \\
\text { during the } \\
1^{\text {st }} \text { year } \\
\text { (3 } \\
\text { rd } \text { group) }\end{array}$ & 6 & $14.3 \pm 0.1$ & $0.67 \pm 0.04$ & $0.36 \pm 0.06$ & $0.53 \pm 0.06$ & $\begin{array}{c}1.03 \pm \\
0.09\end{array}$ \\
\hline \multirow{3}{*}{$\mathrm{P}$} & 1 vs. 2 & & 0.001 & 0.05 & & 0.001 \\
\hline & 1 vs. 3 & & & & 0.001 & \\
\hline & 2 vs. 3 & & 0.001 & & 0.001 & 0.01 \\
\hline
\end{tabular}

Table 7. ACMS in patients who died within three years.

All 18 patients were divided into 3 groups: the $1^{\text {st }}$ group $(n=7)$ consisted of patients who died during the third year of investigation, the $2^{\text {nd }}$ group $(n=5)$ of patients who died during the second year of investigation, and the $3^{\text {rd }}$ group $(n=6)$ of patients who died during the first year of investigation. Patients who died during the first year after coronarography had the most diminished average SCCA, but their left-ventricular ejection fraction was normal. These patients usually experienced a sudden coronary death. However, the patients who died later, during the 2nd year after investigation, had not only a lower ACI but also a lower left-ventricular ejection fraction. They usually died from heart failure. It is interesting to point out that these patients had a worse API and a normal AAI. They did not have typical anginal symptoms. The patients with a lower ACI and a decreased LVEF lived slightly longer despite the fact that they had clinical symptoms of heart failure but they were treated more intensively. It is very important to emphasize that inadequacy between ACI and ejection fraction, when left ventricular hypertrophy has developed, increases the risk for sudden cardiac death. This is a consequence of expressed multi-vessel CAD in patients with viable myocardial hypertrophy. In patients who survived three years, the left-ventricular ejection fraction, ACI and API were better. Therefore, we believe that the survival and death of patients with CAD can be better predicted with the help of ACMS. The product of both angiographic criteria (the ACI expressing the supply adequacy to the myocardial mass and the anginal index expressing the adequacy of supply to the functional requirements) could be the most informative prognostic index of survival in CAD. The product of ACI and $\mathrm{ACI} / \mathrm{EF}$ could be named the angiographic outcome index (AOI). Mathematically, it can be calculated using the following equation: 


$$
\mathrm{AOI}=\mathrm{ACI} \times(\mathrm{ACI} / \mathrm{EF})=(\mathrm{SCCA} / \mathrm{LVM}) \times(\mathrm{SCCA} / \mathrm{LVM}) / \mathrm{EF}=\mathrm{SCCA}^{2} / \mathrm{LVM}^{2} \times \mathrm{EF}
$$

In the equation above the ACI stands for the angiographic coronary index, AOI angiographic outcome index, SCCA -- summarized caliber of coronary arteries $\left(\mathrm{mm}^{2}\right), \mathrm{LVM}$ - mass of the left ventricle (g), and EF - ejection fraction of the left ventricle. The AOI was statistically different in all three groups of patients who died during the $1^{\text {st }}, 2^{\text {nd }}$, or $3^{\text {rd }}$ year after intervention. It was subsequently $0.1 \pm 0.03,0.33 \pm 0.02$, and $0.5 \pm 0.02(\mathrm{p}<0.009, \mathrm{p}<$ 0.001 , and $\mathrm{p}<0.007)$.

\section{Discussion}

The quantification of coronary stenosis is an important practice in cardiology from both a clinical and a research standpoint. In the recent past, there have been several imaging methods which could differently characterize the size and severity of obstructive CAD: coronary angiography, computed tomography, magnetic resonance imaging, and intravascular ultrasound. Various techniques with differing degrees of sophistication were used to measure the amount of luminal narrowing. Each method has provided new opportunities for a more thorough understanding of the pathogenesis of ischemic heart disease and variability of clinical picture. Angiography, performed with the use of digital techniques, has been shown to have significant advantages over the above-listed techniques due to its excellent reproducibility and accuracy (Funabaschi et al., 2003; Kalbfleisch et al., 1990; Molloi et al., 2001). However, for the effective computerized assessment of coronary lesion scores, we need to develop programs which can help to determine the size and severity of CAD more accurately. To achieve this aim, the proposed SCCA assessment system could be useful both theoretically and practically. Let us compare this innovative system to other methods of analysis.

All scoring systems have been based on percentage of stenosis evaluation using the "normal" diameter in the adjacent coronary segment. The validity of this reference is in question because coronary atherosclerosis is often diffuse and the adjacent segment could also be narrowed (Marcus et al., 1983; Seiler et al., 1992). In addition, serial segmental narrowing representing a type of diffuse disease is not taken into account because of the absence of a true normal reference segment. To assess the severity of diffuse CAD (with or without segmental narrowing) it is necessary to know what the normal arterial lumen size would be at each segment in the absence of coronary atherosclerosis. Various authors have attempted to solve this problem in different ways (Kucher et al., 2001; Seiler et al., 1992). Kucher et al. (2001) showed that in a population without cardiac disease, women have smaller coronary artery size even after normalization for left ventricular mass. The existence of a gender difference in coronary artery size remains controversial.

Our search for a "normal" diameter at each segment showed that the successful solution to this problem is impossible due to high variability in coronary dominance and branching. However, our experience and several other experimental and clinical reports (Dodge et al., 1992; Roberts C \& Roberts W, 1980; Seiler et al., 1992) have shown a direct relationship between the coronary artery lumen size and the myocardial mass supplied by this artery. Therefore, the variability in coronary diameter and its direct relationship to myocardial mass have led us to propose a methodology which could be used to assess the degree and cause of any imbalance between residual coronary diameter and the supplied myocardial mass. 
An analysis of patients with intact coronary arteries and increased myocardial mass showed that the SCCA can increase along with the degree of myocardial hypertrophy, especially if this process takes place at a young age. This phenomenon does not disturb the balance between SCCA and left ventricular mass. Therefore, the ratio remains normal. In cases of myocardial hypertrophy in older populations where the process of atherosclerosis has begun, the SCCA does not increase in conjunction with myocardial mass. This relative discrepancy is well illustrated by the lowering of the angiographic coronary index. Similar findings have been described by Marcus et al., (1983). Myocardial ischemia is frequently observed in patients with cardiac hypertrophy even when the conduit coronary arteries are normal (Fig. 7.2 and 7.3). Recent studies indicate that impaired coronary reserve in hypertrophied hearts probably occurs because the growth of the coronary bed does not keep pace with increase of cardiac mass (Fig. 7.4). The imbalance between vascular proliferation and muscle growth is probably most severe when the cardiac hypertrophy is caused by pressure overload or atherosclerotic infiltration (Fig. 7.5). These observations suggest that abnormalities in the coronary microcirculation which accompany cardiac hypertrophy play a significant role in the pathogenesis of the complications associated with cardiac hypertrophy.

The diminishing ACI in people without blockage of epicardial coronary arteries usually is associated with the onset of typical or atypical anginal symptoms. Syndrome $X$ can be associated with chest pain and chest discomfort in people who do not show signs of obstruction in the larger coronary arteries. No one knows exactly what causes Syndrome $X$ and it is unlikely to have a single cause. Today, we speculate that Syndrome $X$ may be caused by microvascular dysfunction. A large majority of women have typical anginal symptoms which are not associated with the presence of atherosclerotic plaques. Scientists speculate that the blood vessels in these women are diffusely abnormal and smaller than in males (Kucher et al., 2001). It is possible that the diminishing ACI is a causative factor in the development of Syndrome X.

Additionally, the relationship between the angiographic coronary index and the functional status of the left ventricle expressed by ejection fraction may specify the adequacy of myocardial supply to myocardial functional demands. First, the inadequacy of myocardial supply with the inadequacy of myocardial nutritional requirements may lead to the occurrence of ischemic pain and its severity. The relationship between the angiographic coronary index and the ejection fraction we named the angiographic anginal index, because we found a strong negative correlation between this index and the intensity of angina.

Recent techniques have revealed new characteristics and expanded our understanding of painless or silent myocardial ischemia. These techniques include treadmill exercise testing; radioisotope techniques, including ejection fraction studies, stress thallium scintigraphy, and tomographic imaging. These new noninvasive tests should be used to detect transient ischemia, estimate its severity, and measure patient's risk for adverse coronary events especially in patients with painless or silent myocardial ischemia (Selwyn, 1990). Usage of anginal angiographic index in clinical practice can facilitate the selection of such high-risk patients with silent ischemia. Patients with diabetes, chronic renal insufficiency and other coexisting diseases have an increased prevalence of coronary artery disease with silent myocardial ischemia, complex ventricular arrhythmias, atrial fibrillation, and left ventricular hypertrophy (Das et al., 2006; Chipkin et al., 1987). These risk factors for cardiovascular morbidity and mortality contribute to the increased incidence of 
cardiovascular morbidity and mortality seen in patients with the above mentioned concomitant diseases (Selwyn, 1990). It is also important to stress that the energy needs of the left ventricle are not always proportional to the ejection fraction. LVEF can be permanently reduced due to post-infarction scar development, but the LVEF may temporarily decrease due to inadequate blood supply to the heart muscle. This phenomenon is known as myocardial hibernation (Camici et al., 2008). In both situations with the disappearance of anginal pain the occurrence of symptomatic heart failure can manifest with the clinical symptoms of ischemic cardiomyopathy (Felker et al., 2002).

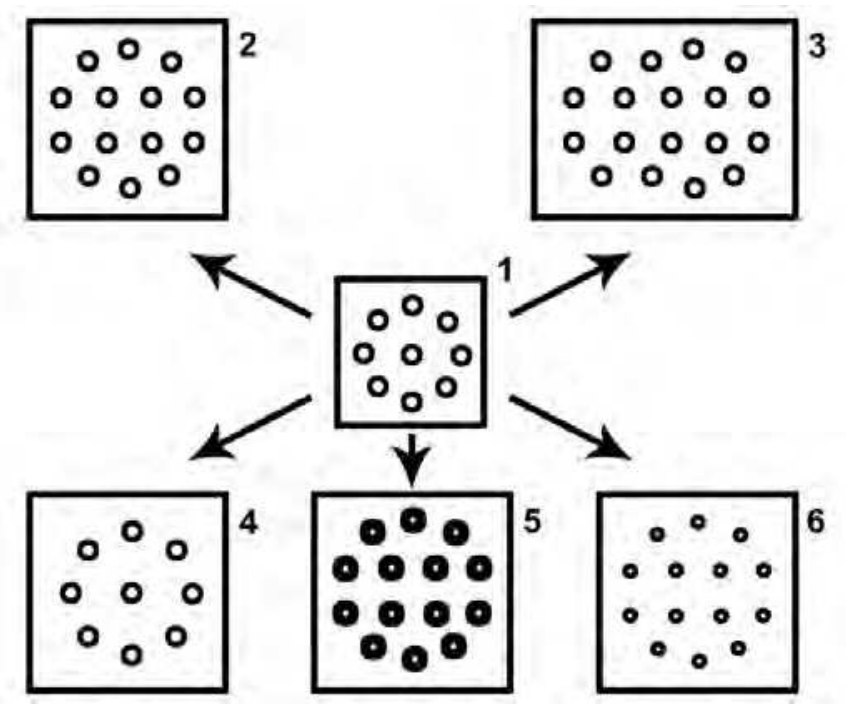

Fig. 7. Changes occurring in the coronary angiogenesis during development of myocardial hypertrophy. The size of the square indicates the presence of myocardial hypertrophy and its degree. The number and size of vessels are shown in each shape: 1, normal number of vessels in non-hypertrophied myocardium; 2 and 3, increased number of normal vessels in hypertrophied myocardium; 4 , the non-increased number of normal vessels in hypertrophied myocardium; 5 , increased number of atherosclerotic thickened-wall vessels in hypertrophied myocardium; and 6, increased number of spastic vessels in hypertrophied myocardium.

The diagnostic value of angiographic anginal index can be confirmed by the fact that during the development of myocardial hibernation or ischemic cardiomyopathy anginal pain reduces and can disappear completely. During the last decade, the existence of totally asymptomatic myocardial ischemia has been conclusively established. We would like to emphasize that the severity of angina depends upon the inadequacy between myocardial nutrition and functional demand, and this was shown by the angiographic anginal index. This index reflecting the adequacy between myocardial supply and demand cannot express the real degree of coronary and myocardial damage, because there may be a supply-demand adequacy in patients with equally expressed damage in the coronary arteries and the myocardium. Knowing the limited prognostic capabilities of the angiographic anginal index, we have created the angiographic outcome index for outcome prediction, and the angiographic prognostic indexes. 
The prognostic capabilities of different coronary scores were confirmed by several authors (Friesinger et al., 1970; Graham et al., 1999; Korosoglou et al., 2007; Ringqvist 1983). The complex angiographic coronary index, anginal index, and left-ventricular ejection fraction are more informative for predicting CAD outcomes. It was shown that only an increase in LV mass in initially healthy persons with essential hypertension resulted in more complications and deaths (Koren et al., 1991). Differently determined left ventricular hypertrophy is an important prognostic marker in patients with or without coronary artery disease (Ghali et al., 1992). It was shown that only reduced LVEF has a clear predictive value in patients without known obstructive CAD. Reduced LVEF was related to sudden death from the absolute presence of CAD as well as the increased number of vessels with obstruction (Min et al., 2010).

\subsection{Limitations}

We have measured the lumen areas of different segments at their narrowest points on coronarograms in this study. Very small measurements sometimes cannot be done without interpretative errors; however, the margin of error is not high. The possibility of underestimating the impact of a single expressed lesion on the diminishing SCCA could be a limitation of this method. It is well known that such single-culprit lesions may cause the development of acute myocardial infarction. However, the main goal of this quantitative analysis system is to assess the total real size and severity of the epicardial coronary lesion using the SCCA as a coronary score.

\section{Conclusion}

The most important advantage of this SCCA calculation system is that it provides an easier and more objective assessment of an angiographic coronary lesion score in patients with a wide spectrum of $\mathrm{CAD}$, ranging from a minimal stenosis to extensive diffuse involvement of the coronary arteries. The SCCA as a coronary lesion score is simple and easily interpreted; it gives no reason for interpretative differences. First, the estimation of the average SCCA does not require a precise assessment of stenosis degree, coronary dominance, or branching peculiarities. Second, it provides the possibility to analyze the relationship between coronary score and myocardial function what implies a correlation between myocardial supply and demand. In addition, this quantitative analysis system can give more diagnostic and prognostic information about the real mechanisms of myocardial ischemia, the character of angina pectoris, and the possible risk for occurrence of life threatening complications. Furthermore, the technique for interpretation of angiographic data and computation of quantitative characteristics has been considerably facilitated.

\section{Acknowledgment}

I would like to thank the staff of the Department of Clinical Pathology, Lithuanian University of Health Sciences for their valuable assistance in performing post-mortem examinations.

\section{References}

Brandt, P.; Partridge, J. \& Wattie, W. (1977). Coronary arteriography: method of presentation of the arteriogram report and a scoring system. Clin Radiol, Vol. 28, pp. 361-365, ISSN 0009-9260 
Brown, B.; Bolson, E.; Frimer, M. \& Dodge, H. (1977). Quantitative coronary arteriography: estimation of dimensions, hemodynamic resistance, and atheroma mass of coronary artery lesions using the arteriogram and digital computation. Circulation, Vol. 55, pp. 329-337, ISSN 0009-7322

Camici, P.; Prasad, S. \& Rimoldi, O. (2008). Stunning, hibernation, and assessment of myocardial viability. Circulation, Vol. 117, pp. 103-114, ISSN 1524-4539

Chipkin, S.; Frid, D.; Alpert, J.; Baker, S.; Dalen, J. \& Aronin, N. (1987). Frequency of painless myocardial ischemia during exercise tolerance testing in patients with and without diabetes mellitus. Am J Cardiol, Vol. 59, pp. 61-55, ISSN 0002-9149

Das, M.; Aronow, W.; McClung, J. \& Belkin, R. (2006). Increased prevalence of coronary artery disease, silent myocardial ischemia, complex ventricular arrhythmias, atrial fibrillation, left ventricular hypertrophy, mitral annular calcium, and aortic valve calcium in patients with chronic renal insufficiency. Cardiol Rev, Vol. 14, pp. 14-17, ISSN 1061-5377

Davies, M. (2000). The pathophysiology of acute coronary syndromes. Heart, Vol. 83, pp. 361-366, ISSN 1355-6037

Dodge, J.; Brown, B.; Bolson, E. \& Dodge, H. (1988). Intrathoracic spatial location of specified coronary segments on the normal human heart. Applications in quantitative arteriography, assessment of regional risk and contraction, and anatomic display. Circulation, Vol. 78, pp. 1167-1180, ISSN 0009-7322

Dodge, J., Brown, B.; Bolson, E. \& Dodge, H. (1992). Lumen diameter of normal human coronary arteries. Influence of age, sex, anatomic variation, and left ventricular hypertrophy or dilation. Circulation, Vol. 86, pp. 232-246, ISSN 0009-7322

Felker , G.; Shaw, L. \& O'Connor, C. (2002). A standardized definition of ischemic cardiomyopathy for use in clinical research. J Am Coll Cardiol, Vol. 39 pp. 210-218, ISSN 0735-1097

Friesinger, G.; Page, E. \& Ross, R. (1970). Prognostic significance of coronary arteriography. Trans Assoc Am Physicians, Vol. 83, pp. 78-92. ISSN 0066-9458

Funabashi, N.; Kobayashi, Y.; Perlroth, M. \& Rubin, G. (2003). Coronary artery: quantitative evaluation of normal diameter determined with electron-beam CT compared with cine coronary angiography initial experience. Radiology, Vol. 226, pp. 263-271, ISSN 0033-8419

Garg, S.; Sarno, G.; Garcia-Garcia, H.; Girasis, C.; Wykrzykowska, J.; Dawkins, K.; et al. (2010). A new tool for the risk stratification of patients with complex coronary artery disease: the Clinical SYNTAX Score. Circ Cardiovasc Interv, Vol. 3, pp. 317326, ISSN 1941-7632

Gensini, G.; Kelly, A.; Da Costa, B. \& Huntington, P. (1971). Quantitative angiography: the measurement of coronary vasomobility in the intact animal and man. Chest, Vol. 60, pp. 522-530, ISSN 0002-9149

Gensini G. (1983). A more meaningful scoring system for determining the severity of coronary heart disease. Am J Cardiol, Vol. 51, p. 606, ISSN 0012-3692

Ghali, J.; Liao, Y.; Simmons, B.; Castaner, A.; Cao, G. \& Cooper, R. (1992). The prognostic role of left ventricular hypertrophy in patients with or without coronary artery disease. Ann Intern Med, Vol. 117, pp. 831-836, ISSN 0003-4819

Gibson, C.; Cannon, C.; Murphy, S.; Marble, S.; Barron, H. \& Braunwald, E. (2002). Relationship of the TIMI myocardial perfusion grades, flow grades, frame count, and percutaneous coronary intervention to long-term outcomes after thrombolytic administration in acute myocardial infarction. Circulation, Vol. 105, pp. 1909-1913, ISSN 1524-4539 (Electronic) 
Gibson, C.; Goel, M.; Murphy, S.; Dotani, I.; Marble, S.; Deckelbaum, L. et al. (2000). Global impairment of coronary blood flow in the setting of acute coronary syndromes (a RESTORE substudy). Randomized efficacy Study of Tirofiban for Outcomes and Restenosis. Am J Cardiol, Vol. 86, pp. 1375-1377, A5, ISSN 0002-9149

Gibson, C.; Murphy, S.; Rizzo, M.; Ryan, K.; Marble, S.; McCabe, C.; et al. (1999). Relationship between TIMI frame count and clinical outcomes after thrombolytic administration. Thrombolysis in Myocardial Infarction (TIMI) Study Group. Circulation, Vol. 99, pp. 1945-1950, ISSN 1524-4539 (Electronic)

Goldstein, J.; Demetriou, D.; Grines, C.; Pica, M.; Shoukfeh, M. \& O'Neill, W. (2000). Multiple complex coronary plaques in patients with acute myocardial infarction. $N$ Engl J Med, Vol. 343, pp. 915-922, ISSN 0028-4793

Graham, M.; Chambers, R. \& Davies, R. (1999). Angiographic quantification of diffuse coronary artery disease: reliability and prognostic value for bypass operations. $J$ Thorac Cardiovasc Surg, Vol. 118, pp. 618-627, ISSN 0022-5223

Hamsten, A.; Walldius, G.; Szamosi, A.; Dahlen, G. \& de Faire, U. (1986). Relationship of angiographically defined coronary artery disease to serum lipoproteins and apolipoproteins in young survivors of myocardial infarction. Circulation, Vol. 73, pp. 1097-1110, ISSN 0009-7322

Jalal A. ( 2007). An objective method for grading of distal disease in the grafted coronary arteries. Interact Cardiovasc Thorac Surg, Vol. 6, pp. 451-455, ISSN 1569-9285 (Electronic)

Jenkins, P.; Harper, R. \& Nestel, P. (1978). Severity of coronary atherosclerosis related to lipoprotein concentration. Br Med J, Vol. 2, pp. 388-391, ISSN 0007-1447

Kalbfleisch, S.; McGillem, M.; Pinto, I.; Kavanaugh, K.; DeBoe, S. \& Mancini, G. (1990). Comparison of automated quantitative coronary angiography with caliper measurements of percent diameter stenosis. Am J Cardiol, Vol. 65, pp. 1181-1184, ISSN 0002-9149

Koren, M.; Devereux, R.; Casale, P.; Savage, D. \& Laragh, J. (1991). Relation of left ventricular mass and geometry to morbidity and mortality in uncomplicated essential hypertension. Ann Intern Med, Vol. 114, pp. 345-352, ISSN 0003-4819

Korosoglou, G.; Haars, A.; Michael, G.; Erbacher, M.; Hardt , S.; Giannitsis, E. et al. (2007). Quantitative evaluation of myocardial blush to assess tissue level reperfusion in patients with acute ST-elevation myocardial infarction: incremental prognostic value compared with visual assessment. Am Heart J, Vol. 153, pp. 612-620, ISSN 1097-6744 (Electronic)

Krone, R.; Laskey, W.; Johnson, C.; Kimmel, S.; Klein, L.; Weiner, B. et al. (2000). A simplified lesion classification for predicting success and complications of coronary angioplasty. Registry Committee of the Society for Cardiac Angiography and Intervention. Am J Cardiol, Vol. 85, pp. 1179-1184, ISSN 0002-9149

Kucher, N.; Lipp, E.; Schwerzmann, M.; Zimmerli, M.; Allemann Y. \& Seiler, C. (2001). Gender differences in coronary artery size per $100 \mathrm{~g}$ of left ventricular mass in a population without cardiac disease. Swiss Med Wkly, Vol. 131, pp. 610-615, ISSN $1424-7860$

Kunadian, V.; Harrigan, C.; Zorkun, C.; Palmer, A.; Ogando, K.; Biller, L. et al. (2009). Use of the TIMI frame count in the assessment of coronary artery blood flow and microvascular function over the past 15 years. J Thromb Thrombolysis, Vol. 27, pp. 316-328, ISSN 1573-742X (Electronic) 
Kwon, S.; Kim, Y.; Shim, J.; Sung, J.; Han, M.; Kang, D. et al. (2011). Coronary artery calcium scoring does not add prognostic value to standard 64-section CT angiography protocol in low-risk patients suspected of having coronary artery disease. Radiology, Vol. 259, pp. 92-99, ISSN 1527-1315 (Electronic)

Leaman, D.; Brower, R.; Meester, G.; Serruys, P.; van den Brand M. (1981). Coronary artery atherosclerosis: severity of the disease, severity of angina pectoris and compromised left ventricular function. Circulation, Vol. 63, pp. 285-299, ISSN 00097322

Marcus, M.; Koyanagi, S.; Harrison, D.; Doty, D.; Hiratzka, L. \& Eastham, C. (1983). Abnormalities in the coronary circulation that occur as a consequence of cardiac hypertrophy. Am J Med, Vol. 75, pp. 62-66, ISSN 0002-9343

Min, J.; Lin, F.; Dunning, A.; Delago, A.; Egan, J.; Shaw, L. et al. (2010). Incremental prognostic significance of left ventricular dysfunction to coronary artery disease detection by 64-detector row coronary computed tomographic angiography for the prediction of all-cause mortality: results from a two-centre study of 5330 patients. Eur Heart J, Vol. 31, pp. 1212-1219, ISSN 1522-9645 (Electronic)

Molloi, S.; Kassab, G. \& Zhou, Y. (2001). Quantification of coronary artery lumen volume by digital angiography: in vivo validation. Circulation, Vol. 104, pp. 2351-2357, ISSN 1522-9645 (Electronic)

Ringqvist, I.; Fisher, L.; Mock, M.; Davis, K.; Wedel, H.; Chaitman, B. et al. (1983). Prognostic value of angiographic indices of coronary artery disease from the Coronary Artery Surgery Study (CASS). J Clin Invest, Vol. 71, pp. 1854-1866, ISSN 0021-9738 (Linking)

Roberts, C. \& Roberts, W. (1980). Cross-sectional area of the proximal portions of the three major epicardial coronary arteries in 98 necropsy patients with different coronary events. Relationship to heart weight, age and sex. Circulation, Vol. 62, pp. 953-959, ISSN 0009-7322

Seiler, C.; Kirkeeide, R. \& Gould, K. (1992). Basic structure-function relations of the epicardial coronary vascular tree. Basis of quantitative coronary arteriography for diffuse coronary artery disease. Circulation, Vol. 85, pp. 1987-2003, ISSN 0009-7322

Selwyn, AP. (1990). Current technology in assessing painless and painful ischemia. Am Heart J, Vol. 120, pp. 722-725, ISSN 0002-8703

Sianos, G.; Morel, M.; Kappetein, A.; Morice, M.; Colombo, A.; Dawkins, K. et al. (2005). The SYNTAX Score: an angiographic tool grading the complexity of coronary artery disease. EuroIntervention, Vol. 1, pp. 219-227, ISSN 1774-024X

Sullivan, D.; Marwick, T. \& Freedman, S. (1990). A new method of scoring coronary angiograms to reflect extent of coronary atherosclerosis and improve correlation with major risk factors. Am Heart J, Vol. 119, pp. 1262-1267, ISSN 0002-8703

Vogt, M.; Motz, W. \& Strauer, B. (1992). Coronary haemodynamics in hypertensive heart disease. Eur Heart J, Vol. 13 Suppl D, pp. 44-49, ISSN 0195-668X

Zaacks, S.; Allen, J.; Calvin, J.; Schaer, G.; Palvas, B.; Parrillo, J. et al. (1998 ). Value of the American College of Cardiology/American Heart Association stenosis morphology classification for coronary interventions in the late 1990s. Am J Cardiol, Vol. 82, pp. 3-9, ISSN 0002-9149

Zipes, D. \&Wellens, H. (1998). Sudden cardiac death. Circulation, Vol. 98, pp. 2334-2351, ISSN 0009-7322 


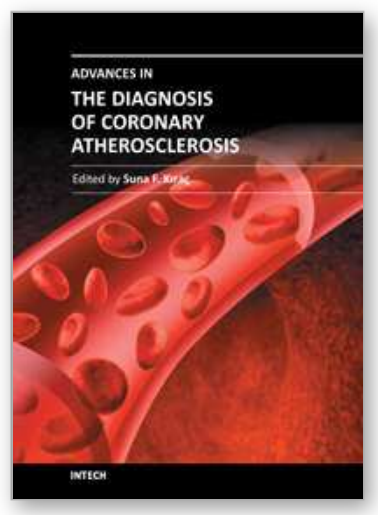

\author{
Advances in the Diagnosis of Coronary Atherosclerosis \\ Edited by Prof. Suna Kirac
}

ISBN 978-953-307-286-9

Hard cover, 378 pages

Publisher InTech

Published online 09, November, 2011

Published in print edition November, 2011

Coronary artery disease $(C A D)$ and its consequences are most important morbidity and mortality reasons in the developed and developing countries. To prevent hard end-points, early definitive diagnosis and optimum therapy play significant role. Novel advanced diagnostic tests which are biomarkers of inflammation, cell adhesion, cell activation and imaging techniques provide to get the best result in the detection and characterization of calcified or uncalcified atherosclerotic plaques. In spite of last developments in the imaging methods, coronary catheterization is still frequently performed. Following the first cardiac catheterization performed in 1844, date by date historical developments and the mechanics of cardiac catheterization techniques, risks associated with coronary angiography, and also, preventions and treatments of possible complications have been presented in this book. Other important issue is radiation exposure of patients and staff during coronary angiography and scintigraphy. Radiation dose reduction techniques, general radiation protection principles have been discussed in related chapters.

\title{
How to reference
}

In order to correctly reference this scholarly work, feel free to copy and paste the following:

Edvardas Vaicekavicius (2011). Summarized Coronary Artery Caliber and Left Ventricle Mass for Scoring of Cardiac Ischemia: Diagnostic and Prognostic Value, Advances in the Diagnosis of Coronary Atherosclerosis, Prof. Suna Kirac (Ed.), ISBN: 978-953-307-286-9, InTech, Available from:

http://www.intechopen.com/books/advances-in-the-diagnosis-of-coronary-atherosclerosis/summarizedcoronary-artery-caliber-and-left-ventricle-mass-for-scoring-of-cardiac-ischemia-diagnosti

\section{INTECH}

open science | open minds

\section{InTech Europe}

University Campus STeP Ri

Slavka Krautzeka 83/A

51000 Rijeka, Croatia

Phone: +385 (51) 770447

Fax: +385 (51) 686166

www.intechopen.com

\section{InTech China}

Unit 405, Office Block, Hotel Equatorial Shanghai

No.65, Yan An Road (West), Shanghai, 200040, China 中国上海市延安西路65号上海国际贵都大饭店办公楼 405 单元

Phone: +86-21-62489820

Fax: +86-21-62489821 
(C) 2011 The Author(s). Licensee IntechOpen. This is an open access article distributed under the terms of the Creative Commons Attribution 3.0 License, which permits unrestricted use, distribution, and reproduction in any medium, provided the original work is properly cited. 